\title{
Posturas jurisprudenciales sobre la determinación de la naturaleza jurídica del bien rural en procesos de pertenencia
}

\author{
Jurisprudential positions on the determination of the legal status of rural well in process of belonging
}

*María Clara Ocampo Correa**

*Juez 13 civil del Circuito de Medellín. Abogada de la Universidad de Medellín, Especialista en Derecho Administrativo de la Universidad Santo Tomás sede Bogotá, Especialista en Seguridad Social de la Universidad Autónoma Latinoamericana, Especialista en Derecho de los Seguros de la Universidad y candidata a Magister en Derecho Privado de la Universidad Pontificia Bolivariana sede Medellín.

\begin{abstract}
Resumen
En los procesos de pertenencia de bienes rurales se han presentado diferentes posturas frente a la determinación de la naturaleza jurídica del bien objeto del litigio. Por un lado la Corte Suprema de Justicia se acoge a la presunción legal del bien privado cuando sea poseído con explotación económica, en los términos de la ley 200 de 1936, y si no se desvirtúa puede ser adquirido por prescripción. Por otro lado la Corte Constitucional estima como indicio de bien baldío la falta de propietarios inscritos en el registro y que la demanda sea dirigida contra indeterminados. En el escrito se presentan estas posturas y se apoya la de la Corte Suprema de Justicia con base en la estructura y obligatoriedad de las presunciones legales.
\end{abstract}

Palabras clave: Adjudicación de bienes baldíos, prescripción adquisitiva de dominio, proceso de pertenencia de bien rural, presunción legal, explotación económica, registro inmobiliario.

\begin{abstract}
In the processes of ownership of rural property, different points of view have been presented for the determination of the legal nature of the litigious goods. On the one hand, the Supreme Court of Colombia has recourse to the legal presumption of private good when it is owned together with economic exploitation under the terms of Act 200 of 1936, and if the economic exploitation is kept, the good can be acquired by prescription. On the other hand, the Constitutional Court of Colombia considers as a sign of State-owned land the lack of registered owners and that the fact that the demand is directed against undetermined persons. After the analysis of these points of view, we support the Supreme Court's position based on the structure and mandatory nature of the legal presumptions.
\end{abstract}

Keywords: Adjudication of State-owned land, acquisitive prescription of ownership, processes of ownership of rural property, legal presumption, land registration.

\section{Introducción}

En Colombia los bienes baldíos y la forma de adquirir su propiedad está regulado en la Constitución Política y en normas especiales, principalmente la Ley 200 de 1936 y Ley 160 de 1994, y es reconocido por la jurisprudencia que el Estado ostenta la propiedad sobre estos inmuebles, dado su calidad especial y señalando la imposibilidad de ser
Recepción

18 de julio de 2016

Revisión:

30 de agosto de 2016

Aprobación:

7 de septiembre de 2016 
adquiridos mediante proceso de pertenencia por prescripción adquisitiva de dominio.

Sin embargo, en pronunciamiento recientes de la Corte Constitucional en sentencia T-488 de 2014 y de la Corte Suprema de Justicia (en adelante CSJ) especialmente en sentencia No. 1776-2016, expediente No. 15001-2213-000-2015-00413-01 del año 2016, se observa discrepancia de posturas en cuanto a aspectos probatorios dentro de los procesos de pertenencia sobre fundos rurales de los cuales no se tiene certeza sobre su naturaleza jurídica; por un lado la Corte Constitucional otorga fuerza probatoria de indicios a las inscripciones y registros de la matrícula inmobiliaria, y la CSJ, por otro lado, resalta la fuerza vinculante que tiene la presunción consagrada en el artículo $1^{\circ}$ de la Ley 200 de 1936, que versa sobre considerar como privado un bien rural cuando se demuestre su explotación económica por hechos positivos.

Se pretende analizar la postura de la Corte Constitucional frente a la presunción referida y advertir que esta corporación se aparta de la obligatoriedad que existe frente a la presunción legal, por tal motivo la pertinencia de este análisis radica en aceptar, partiendo de la concepción de los bienes baldíos, la aplicación dentro de los procesos de pertenencia de esta presunción para determinar la naturaleza jurídica de un bien tal y como lo expone la CSJ, encontrando mayores argumentos para defenderla, a partir del estudio de la presunción legal doctrinal y jurisprudencial teniendo en cuenta su definición y su fuerza vinculante, y se examina el limitante para el acceso a la propiedad rural que constituye los indicios expuestos por la Corte Constitucional en la Sentencia T 488 de 2014.

\section{La presunción legal y su fuerza vinculante}

En términos generales, la presunción es una inferencia teórica que a partir de premisas lleva a una conclusión que se reputa verdadera porque tiene la característica de regularidad, normalidad o probabilidad de verdad que está compuesta por un hecho base, un hecho presunto y una conexión entre ellos; una característica de la presunción es su derrotabilidad es decir cuando se cuenta con más información es más probable determinar o fijar con mayor certeza la verdad material (Aguiló, 2006). Para Mendoca (2000) las presunciones legales son mandatos de ley que obligan a tener por fundado un hecho, cuando la ocurrencia de otro que es indicador de su existencia sea acreditado suficientemente.

Las presunciones legales al ser establecidas y determinadas por el legislador, reconocen relaciones "lógicamente posibles" que son aceptadas y ocurren con cierta habitualidad, entonces, al admitirlas sele brindauna protección a bienes con un carácter jurídico valioso. (Corte Constitucional, Sentencia C-388 de 2000). El artículo 66 del Código Civil (en adelante CC) dispone que se presumen los hechos que se deduzcan de ciertas circunstancias conocidas, que cuando son determinados por la ley se llaman presunción legal, y admiten prueba en contrario para demostrar que el hecho que legalmente se presume no es cierto aunque los antecedentes lo sean.

De acuerdo con Zavala (1991), la presunción legal establece una consecuencia que es el resultado de una relación entre un hecho conocido y cierto con un hecho incierto $y$ desconocido, la cual debe estar expresada en una norma jurídica y es cierta mientras no se pruebe lo contrario; de esta manera para el autor las presunciones están compuestas por tres elementos, (i) una afirmación base que debe estar acreditada totalmente, (ii) afirmación resultado, consecuencia o presumida, y (iii) el enlace que permite la transición entre la afirmación base probada y la presumida, que esta subsumida en una norma. El hecho presunto o resultado es el punto de mayor importancia de la presunción, ya que es el supuesto fáctico de la norma que el demandante quiere que se 
aplique al caso, es decir, es la pretensión de la demanda (Álvarez, 2007).

Aguiló (2006) describe tres formas de oponerse a la regla de la presunción (i) negar los fundamentos empíricos de la presunción, es decir, desconocer que la regla sea normal, regular o tenga probabilidad de verdad (ii) aceptar la regla de la presunción pero negar la ocurrencia del hecho base, y (iii) aceptar la presunción y el hecho base pero demostrar que la presunción es falsa o que hay indicios para acreditar que el caso es una excepción a la regla.

Las presunciones cumplen con el fin de aproximar la verdad en el sentido material y distribuir la carga de la prueba o de la argumentación (Aguiló, 2006), es decir, en un proceso, las presunciones sirven para crear una verdad procesal ante la falta de certeza de la verdad material y además, traslada la carga de la prueba o de la argumentación para oponerse al hecho presunto a través de demostrar la no ocurrencia del hecho base.

Así mismo, las presunciones tienen una finalidad judicial consistente en limitar la arbitrariedad en la apreciación de las pruebas, ya que ante la acreditación de un hecho debe darse por cierto el hecho presumido puesto que el legislador impuso una solución con base en las máximas de la experiencia de la cual el juzgador no puede apartarse; de esta manera, las reglas de presunción aplicadas en los proceso judiciales llevan al juez a aplicarlas cuando se acreditan los hechos que constituyen la afirmación o hecho base, a menos que se pruebe la inexistencia o falta de veracidad del hecho base o del hecho presumido (Zavala, 1991).

Según Aguiló (2006) el juez está obligado a utilizar la regla de la presunción para resolver el caso en los que la norma sea aplicable, toda vez que la función principal de la presunción es establecer una verdad procedimental, es decir, conforme con la presunción el juez debe declarar probado o no un hecho de acuerdo con las circunstancias del caso. En igual sentido dice Mendoca (2000) que como las presunciones señalan anticipadamente una respuesta a un caso en litigio, en virtud de la ley que prescribe la presunción, el juez debe resolver el caso tomando como cierto el hecho controvertido a partir de la acreditación de un hecho base, mientras no existan elementos de prueba en contra.

Al respecto dice Palomo que las presunciones legales imponen al juzgador entender un hecho (hecho presunto) alegado por una parte como verdadero sin que se pruebe directamente si la contraparte no logra demostrar lo contrario (2013), es decir, en las reglas de la presunción siempre el que alega la presunción debe probar el hecho base para tenerse como acreditado el hecho presunto, e impone al demandado un deber de contraprobar el hecho base para contradecir el hecho presunto.

En cuanto a la regulación de la presunción aplicada a los procedimientos, el artículo 166 del Código General del Proceso, en adelante CGP, (Art. 176 Código de Procedimiento Civil CPC) dispone que las presunciones legales proceden siempre y cuando los hechos en que se funden estén debidamente probados, admitiendo prueba en contrario.

La presunción tiene efectos en el tema probatorio al beneficiar a la parte favorecida por la presunción ya que le ahorra probar los presupuestos fácticos de una norma para en cambio acreditar los hechos bases de una presunción. (Álvarez, 2007), es decir se presenta una modificación en el objeto de la prueba ya que es necesario probar el hecho base de la estructura de la pretensión y no el hecho presunto que es el supuesto fáctico de la norma contenida en la pretensión la cual el demandante quiere hacer valer en juicio.

En igual sentido, de acuerdo con la doctrina, las presunciones legales no son estrictamente un 
auténtico medio de prueba, porque establecen la verdad procesal de un hecho obligando a tenerlo por cierto sin que sea necesario la prueba del mismo, así, la carga probatoria versa sobre el hecho base y no sobre el hecho presumido que de acuerdo con la ley se tiene por cierto (Casino, 2010). Para Álvarez (2007) la presunción legal son métodos de prueba o de valoración de la misma toda vez que sirven para la formación de la convicción del juzgador sobre los hechos que sean relevantes en un proceso, específicamente en la pretensión procesal de la parte demandante.

Ahora bien, existe un concepto similar a la presunción que se conoce como indicio que tiene tres elementos, el hecho conocido, la inferencia lógica y el hecho desconocido (Zavala, 1991). El silogismo del indicio comprende tres elementos principales, premisa mayor que consistiría en una experiencia o práctica que se ha fundado; premisa menor, como una comprobación del hecho; y conclusión que sale de la concreción de la premisa mayor en la premisa menor (Bueso, 2001-2002). Para Peláez (1974) el indicio es una deducción que realiza el juez mediante la inferencia de ciertos hechos que se prueban en un proceso, es decir, consiste en considerar la existencia de un hecho a partir de la acreditación de otro.

Aunque los indicios pueden producir efectos en el convencimiento del juez, no pueden tenerse como plena prueba para para resolver un caso en concreto, porque no tienen tanta importancia como las presunciones (Bueso, 2001-2002), ya que si bien la presunción y el indicio comparten una estructura similar, el enlace o la inferencia lógica en el caso de la presunción se encuentra en la ley en cambio en el indicio la inferencia está en el raciocinio del juez (Zavala, 1991).

La presunción legal de propiedad privada por la explotación económica del bien rural para adquirir mediante prescripción adquisitiva de dominio (artículo $1^{\circ}$ ley 200 de 1936)
Antes de explicar la presunción de que trata el artículo 1 de la Ley 200 de 1936, cabe aclarar que la propiedad privada es aquella que se ejerce sobre un bien mueble, inmueble o inmaterial, pudiendo disponer de este, además de ejercer sobre él un uso, goce y disfrute. (Corte Constitucional, C-189 de 2006). En algunos casos la propiedad se puede adquirir por medio de la prescripción adquisitiva de dominio, ordinaria o extraordinaria; la cual es un modo de adquirir y extinguir obligaciones y derechos. En caso concreto, la prescripción adquisitiva es un modo de adquirir bienes y derechos partiendo de la posesión de estos, siempre y cuando se cumplan los requisitos que en la ley se estipulan, en la legislación colombiana la prescripción está consagrada en el artículo 2512 del CC.

Para solicitar la declaración de pertenencia de un bien inmueble por haber operado la prescripción adquisitiva del dominio se debe iniciar un proceso de pertenencia bajo los requisitos que trae el artículo 375 del CGP (Artículo 407 del CPC), el cual dispone que sólo se podrá incoar esta acción contra bienes que no sean imprescriptibles, además que al escrito de la demanda se deberá acompañar certificado del registrador de instrumentos públicos donde consten las personas titulares de derechos reales, y explica el procedimiento para notificación. De esta manera ante una latente antinomia entre los artículos 2517 y 2519 del CC, que disponen que la prescripción se aplica en favor y en contra de la nación y de los particulares y que los bienes de uso público son imprescriptibles, respectivamente, el artículo 407 del CPC dispuso que la declaración de pertenencia no procede frente a los bienes imprescriptibles o de propiedad de las entidades de derecho público, quedando así claro y respaldado por la doctrina y la jurisprudencia que los bienes estatales no pueden ser adquiridos por prescripción adquisitiva de dominio. 
Por otro lado, el artículo 675 del Código Civil establece una presunción legal consistente en que "[s]on bienes de la Unión todas las tierras que estando situadas dentro de los límites territoriales carecen de otro dueño", es decir, mientras no se repute un tercero como dueño de un fundo, se presume que es de la Nación. El Código Civil en el artículo 762 presenta una presunción legal que favorece la prueba de la posesión en tanto dispone que "el poseedor es reputado dueño mientras otra persona no justifique serlo", así quien acredita la posesión de un bien podrá alegar su propiedad y sólo se desvirtuará si un tercero logra probar el dominio del mismo bien.

Ahora bien, los bienes baldíos son aquellos que nunca han salido del patrimonio o dominio del Estado, es decir no han tenido dueño particular y pertenecen al estado (Ochoa, 2006). La pertenencia sobre los bienes baldíos la ostenta la Nación, la cual podrá disponer de su adjudicación a particulares o entidades públicas estipulando unas restricciones que ha materializado el legislador en las leyes sobre bienes baldíos. (Corte Constitucional, 1997).

Los bienes rurales baldíos son adquiridos mediante resolución de adjudicación expedida por la entidad competente, así la ley 160 de 1994 (art. 65) y su decreto reglamentario 2664 de 1994 (art. 3) disponen que los baldíos adjudicables únicamente pueden adquirirse mediante título traslaticio de dominio expedido por el Instituto Colombiano de Desarrollo Rural (en adelante INCODER) o la entidad pública que haga sus veces, en razón a que los bienes públicos son imprescriptibles. El artículo 48 de la Ley 160 de 1994, dispone que para clarificar la situación de las tierras, la propiedad privada se deberá acreditar mediante título originario o cadenas traslaticias de dominio.

En cuanto a la presunción legal objeto de estudio, la Ley 200 de 1936 en su artículo $1^{\circ}$ (modificado por el artículo $2^{\circ}$ de la ley 4 de 1973) dispone que los bienes raíces poseídos por particulares se presumen de propiedad privada, es decir no baldíos, siempre y cuando la posesión consista en explotación económica del suelo a través de hechos positivos propios del dueño con explotación económica, verbigracia plantaciones u ocupaciones con ganado.

Cabe advertir que esta presunción no es aplicable a los bienes urbanos, ya que de acuerdo con la ley 137 de 1958 se presumen propiedad del Estado los bienes que se encuentran dentro de la zona urbana de los municipios, propiedad que fue cedida a cada municipio bajo la condición de que fueran vendidos dichos terrenos a los propietarios de las mejoras con anterioridad a la vigencia de la ley y dentro de los dos años siguientes a esta. La presunción podría ser desvirtuada mediante las pruebas que de acuerdo con el ordenamiento jurídico acrediten que el bien sea propiedad privada, así pues, se tiene que frente a los bienes urbanos la presunción es de propiedad del Estado mientras que para los bienes rurales la presunción es propiedad privada cuando se acredita la explotación económica. Así las cosas, los bienes urbanos de los cuales no se tenga certeza sobre su propiedad no están cobijados por la presunción de la ley 200, por ende en el presente escrito se tendrá como objeto los bienes rurales donde se presenta discusión entre estatales o privados.

Respecto a la presunción de los bienes rurales Valencia Zea y Ortiz Monsalve (2007) expresan que es una presunción legal que puede ser desvirtuada si el Estado logra demostrar que un determinado fundo pertenece a reserva nacional. Así mismo, dice el autor que con esta presunción el Estado renuncia a controvertir la propiedad de los predios rurales que sean explotados económicamente y advierte que con esta presunción el poseedor de un predio rural que lo explote económicamente, puede adquirirlo mediante un título de adjudicación que el gobierno le otorgue, que constituya plena prueba de la propiedad y que sea inscrito 
ante la oficina de instrumentos públicos que corresponda.

Para el autor colombiano (2007) el hecho de la explotación económica constituye el supuesto material de la propiedad, pero no sucede lo mismo con la prueba ya que la explotación no establece prueba idónea frente al Estado, puesto que el artículo 24 de la Ley 200 dispone que para acreditar su propiedad sirve una inspección ocular o un título de adjudicación inscrito.

La exigencia de la posesión para presumir que el bien es propiedad privada no se constituye por ejercer actos de señor y dueño como lo exige la posesión civil sino que tiene una exigencia mayor, debe ser con explotación económica del bien (INCODER, 2012) que debe ser principalmente en actividades de ganadería, agricultura y forestal, pero de acuerdo con la Ley 200 , se deja un amplio margen de actividades económicas de otra índole que en cada caso el juzgador deberá analizar si caben dentro de éste término, por esto el simple hecho de una relación material con el inmueble, su cerramiento o construcción de edificios no constituyen actividad económica, es decir no son hechos bases de la regla de presunción; no obstante también pueden ser tenidos en cuenta las porciones incultas que estén vinculadas necesariamente a la explotación económica del resto del predio; la explotación debe ser estable no accidental o transitoria, aunque se pueden presentar interrupciones temporales de acuerdo con los métodos para el descanso de la tierra (Valencia, 2007)

Así entonces, la posesión del predio rural para que se pueda aplicar la pretensión debe tener trascendencia económica para constituirse como elemento necesario y esencial para que exista o se predique su propiedad, de esta manera, esta posesión tiene elementos objetivos verificables que una vez constatados dan lugar a adquirir el inmueble explotado por prescripción adquisitiva de dominio por ser el bien productivo durante el término legal (Consejo Superior de la Judicatura, 2011)

De esta manera, al momento de realizar la declaración de prescripción de un bien que no se tenga certeza sobre la naturaleza, se debe tener en cuenta y priorizar la presunción legal de predio privado por explotación económica, es decir, si un particular tiene la posesión de un fundo en los términos de explotación económica e inicia proceso de declaración de pertenencia, en caso de que exista duda frente a la naturaleza del predio, el INCODER o cualquier contradictor legítimo debe probar que es un baldío, puesto que al demandante lo acoge la presunción anotada; además, esta presunción también debe tenerse en cuenta en la interpretación del artículo 3 del Decreto 2664 puesto que el poseedor del inmueble que esté poseyendo con explotación económica no se presume tierra baldía (INCODER, 2012)

Contrario a la presunción antes expuesta, el artículo 2 de la ley 200 dispone que se presumen baldíos los terrenos que no sean explotados económicamente, al respecto Valencia Zea y Ortiz Monsalve (2007) expresan que también es una presunción que admite prueba en contrario, es decir, se puede demostrar que a pesar de que no sea explotado no es baldío con un título originario acreditando que el fundo salió del dominio estatal o con título inscrito vigente otorgado con anterioridad a la Ley 200.

Valencia Zea y Ortiz Monsalve expresan que la propiedad de los baldíos que se adquiere por adjudicación exige que (i) las tierras sean realmente baldías y que estén destinadas a ser adjudicadas, (ii) que sean explotadas económicamente y (iii) que se obtenga el título de adjudicación por la entidad autorizada para ello (2007).

Por otro lado es pertinente hacer referencia a la función del registro inmobiliario y su historia, dado que el valor probatorio de éste instrumento es de gran importancia dentro de los procesos 
de pertenencia. De esta forma, según lo afirma el autor Caicedo Escobar (2001), en Colombia por medio de varias disposiciones legales se ha planteado la regulación desde el ámbito procedimental de la función registral, sin embargo las normas llamadas a justificar dicha función se encuentran disgregadas en todo el ordenamiento jurídico.

En el estatuto básico de instrumentos públicos, decreto-ley 1250 de 1970, no se establecieron normas diferentes a las que el Código Civil traía en esta materia puesto que sólo se refirió a la funciones instrumentales y administrativas de esta herramienta registral; no obstante este estatuto sufrió posteriormente algunas modificaciones, tales como las producidas por el decreto-ley 2156 de 1970, como otorgar funciones a la Superintendencia de Notariado y Registro para otorgar con preferencias de tiempos en la expedición de certificados que facilitaran los programas de vivienda, y como facultar al Gobierno Nacional por solicitud de la Superintendencia, para que este pueda crear el cargo de registradores delegados, entre otras (Caicedo, 2001).

Luego por medio del decreto-ley 1711 de 1984 se introdujo normas en cuanto al ejercicio de cooperación entre las oficinas de registro y las de catastro, y la modificación de las oficinas de registro en términos administrativos; igualmente con el decreto 2158 de 1992, se le determinó la estructura y las facultades de la Superintendencia de Notariado y Registro y de más funciones que se desprende de la función registral. Sin embargo, en 1997 por medio del decretoley 1669 se derogaron algunas disposiciones del 2158 dado que concentró algunas de las dependencias de la Superintendencia (Caicedo Escobar, 2001). También, se tiene en cuenta el decreto 2280 de 2008, que derogó el decreto 1708 de 1989 y el 1428 de 2000, por el cual se establecieron los derecho por concepto de la función registral. Y finalmente con la ley 1579 de 2012 se expide el nuevo estatuto de registro de instrumentos públicos.
Posturas jurisprudenciales: Una mirada desde la corte constitucional y la corte suprema de justicia.

\section{Postura de la Corte Constitucional}

A continuación se realiza un recuento de las sentencias de la Corte Constitucional sobre bienes baldíos, la función del certificado del registrador de instrumentos públicos y se referencia especialmente la sentencia T-488 de 2014 que trata sobre la necesidad de esclarecer la naturaleza jurídica de los bienes rurales objeto de procesos de pertenencia.

La Corte en sentencia C-595 de $1995^{1}$ expone su posición acerca de la posibilidad de adquirir bienes baldíos, siempre y cuando se haga por medio de las entidades competentes del Estado, precisando que jurídicamente dentro del espectro de la regulación de bienes baldíos se establece la adjudicación por medio de título traslaticio de dominio otorgado por el Estado, y no es posible la adquisición del bien rural a través de la prescripción adquisitiva de dominio puesto que los baldíos son una excepción y se les ha consagrado un régimen especial ${ }^{2}$. La adjudicación se realiza en cumplimiento de requisitos tales como demostrar una ocupación del bien no inferior a cinco años, haber realizado explotación económica, entre otros.

Esta posición se reafirma en sentencia C-530 de 1996, en donde se demanda un aparte del artículo 401 del CPC que versa sobre la improcedencia de la declaración de pertenencia respecto de bienes imprescriptibles 0 de propiedad de las entidades de derecho público, puesto que se considera violatorio de la igualdad porque los bienes privados se pueden adquirir por prescripción, al respecto la Corte

\footnotetext{
1 Se demanda la inconstitucionalidad de los artículos $3^{\circ}$ de la ley 1882, inciso segundo del artículo 65 y aparte del artículo 69 de la ley 160 de 1994 y el artículo 61 de la ley 110 de 1992, todas referentes a la posesión, dominio, adjudicación e imprescriptibilidad de los bienes baldíos, con fundamento en el Estado debe promover la explotación económica y el acceso y propiedad de la tierra, permitiendo la posesión, prescripción y seguidamente propiedad de aquellos bienes que se han considerado baldíos.

2 Ley 48 de 1882, ley 110 de 1912 y ley 160 de 1994
} 
explica que los bienes fiscales hacen parte de la Nación y por tanto el legislador puede imponer un régimen especial para estos.

En esta misma sentencia C-530 de 1996, la Corte afirma que fijar esta restricción no va en contra de los fines del Estado como el de servir a la comunidad, ya que con la existencia de bienes fiscales como los bienes públicos o de uso público se está sirviendo a la comunidad, tanto en el presente como en el futuro, y es por esta gran función que cumplen y su pertenencia a la sociedad, pero con soberanía del Estado, que los hace merecedores de "un tratamiento especial para su protección, a favor de toda la sociedad.

En el mismo sentido, la Corte en sentencia C-097 de 1996 manifiesta que los bienes baldíos además de ser imprescriptibles son inenajenables, es decir, que están por fuera del comercio puesto que son bienes fiscales adjudicables pertenecientes a la Nación, y únicamente cuando sean adjudicados por la entidad competente el particular podrá disponer del bien.

Igualmente esta posición es reafirmada en sentencia C-383 del año 2000, en donde se resalta la imprescriptibilidad de algunos bienes como los fiscales, baldíos y los de uso público puesto que hacen parte del patrimonio del Estado y cumplen una función y utilidad social, fundada en el Estado Social de Derecho, dejando a la vista el respeto y la continuidad del precedente en estos temas.

Respecto al Certificado del Registrador como requisito para el proceso de pertenencia, la Corte afirma que cumple dos funciones, determina la competencia funcional y territorial e indica contra quien debe dirigirse la demanda de pertenencia; ahora, si en el certificado no se señala persona con derechos reales sobre el inmueble porque no hay inscritos o porque no se ha registrado el fundo, conlleva a un certificado negativo, dando lugar a dirigir la demanda contra personas indeterminadas. No obstante, en este último evento se garantiza el derecho al debido proceso y a la defensa de las personas indeterminadas ya que se obliga a la notificación por emplazamiento para que contesten la demanda, y si no se notifican se impone el nombramiento de un curador ad litem para defender sus derechos.

Sobre el certificado del registrador, en sentencia C-275 de 2006 se dijo que su finalidad era garantizar el derecho de defensa mediante la integración de los legítimos contradictores, amparar los principios de seguridad jurídica, eficiencia, celeridad y economía, y dar claridad frente a la titularidad de los derechos reales sujetos a registro sobre el bien objeto del proceso de pertenencia.

De esta manera, se tiene que la Corte Constitucional avala el tratamiento especial que tienen los bienes baldíos, ya que tienen un interés general que proteger, además afirma que el modo de adquirir el dominio es mediante adjudicación de la entidad competente y que la función del certificado de registro es determinar la integración del legítimo contradictor en un proceso donde se pretenda obtener el dominio de un inmueble rural por prescripción adquisitiva. Teniendo claro esto, se da paso a referenciar la sentencia T-488 de 2014 por ser de especial interés para el presente escrito, ya que en ella la Corte Constitucional señala indicios para determinar si un bien es baldío o propiedad privada.

Así, en esta sentencia T-488 de 2014 la Corte resolvió el caso de revisión de tutela donde el accionante solicitó al juez constitucional que se le ampararan sus derechos fundamentales dado que en proceso de pertenencia se le había reconocido el ejercicio de posesión y prescripción adquisitiva de un predio, sin embargo al momento de solicitar la inscripción de la sentencia en la matrícula inmobiliaria del inmueble fue denegada, puesto que la Oficina de Registro argumentó que el bien era un 
baldío y por disposición legal, el Registrador no podía realizar dicha inscripción al ser el Estado el propietario de estos bienes y no ser susceptibles de adquirirlos por la prescripción, sino mediante la adjudicación de una resolución de la entidad pública competente que constituye un título traslaticio de dominio.

Enel trámite de la tutela, el Registrador Seccional como entidad vinculada, apoyó que la solicitud de inscripción fuera denegada, argumentando que los Registradores están llamados a registrar los títulos y documentos que cumplan con las exigencias de la ley, y al ser este un bien baldío iba en contraposición a las disipaciones normativas colombianas. Adicionalmente, como sustento de su intervención, adjuntó 3 conceptos que fundamentan la decisión de no inscripción del bien en litigio, los cuales fueron: i) Consulta 3463 de la Superintendencia de Notariado y Registro ante la Oficina Asesora Jurídica, con fecha del 19 de diciembre de 2011; ii) Concepto SNR-2012-EE-17372 de la Superintendencia de Notariado y RegistroSuperintendente Delegado para la Protección, Restitución y Formalización de Tierras, con fecha de julio de 2012; iii) INCODER, Radicado 20121104030- Directora Técnica de Baldíos, con fecha del primero de marzo de 2012.

En sede de revisión, el INCODER, alega no haber sido vinculado al proceso ordinario de pertenencia realizado en el que se le reconoció la pertenencia al accionante, argumentado que es la entidad competente y responsable de la adjudicación de los bienes baldíos a nombre del Estado, previamente verificando el cumplimiento de unos requisitos expuestos en la ley. Así mismo, este instituto expresa que si un predio no tiene folio de matrícula se debe presumir baldío, y relata que no cuenta con una lista detallada de los bienes considerados baldíos nacionales.

En esta sentencia la Corte reitera lo ya expuesto anteriormente sobre la clasificación de los bienes baldíos, trayendo a colación la sentencia
C-255 de 2012, en la cual se manifiesta que existen bienes fiscales adjudicables, los cuales al ser de propiedad de la Nación, solo podrá ser adjudicados por esta, por medio de sus instituciones competentes, y reafirma la postura de no poder adquirir la propiedad de los bienes baldíos basado en la sentencia C-595 de 1995.

En esta sentencia se referencia la ley 160 de 1994, por medio de la cual se crea el Sistema Nacional de Reforma Agraria y Desarrollo Rural Campesino, señalando el artículo 65 que dispone que la forma de adquirir el dominio de los bienes baldíos es a través de un título traslaticio de dominio otorgado por la entidad competente del Estado.

La Corte Constitucional considera que existió un defecto fáctico en la sentencia que declaró la pertenencia, toda vez que desconoció la realidad probatoria puesto que teniendo allegado al proceso el certificado de la oficina de instrumentos públicos donde no se indica personas titulares de derechos reales sobre el inmueble y que el proceso fue dirigido contra personas indeterminadas, surgían indicios suficientes para pensarse que el bien objeto del proceso era un bien baldío y por tanto imprescriptible.

Así mismo, expresa la Corte que el juez de conocimiento del proceso declarativo omitió decretar de oficio practicar pruebas con el fin de esclarecer efectivamente la naturaleza jurídica del inmueble para determinar el modo de adquirir el dominio, si por prescripción adquisitiva de dominio o por adjudicación de título traslaticio de dominio otorgado por el INCODER. De esta forma el juez del proceso debió solicitar concepto al INCODER sobre la naturaleza del bien objeto del litigio.

Por estos motivos, la Corte defendió la legalidad de la actuación del Registrador al negarse a inscribir la demanda declaratoria de partencia puesto que no cumplía con los requisitos exigidos en la ley, y las Oficinas de Registro 
de Instrumentos Públicos sólo deben registrar los documentos que estén constituidos en legal forma.

Es así como la Corte Constitucional en esta sentencia T-488 del 2014 argumenta la necesidad de determinar con certeza la naturaleza del bien objeto de un proceso de pertenencia para establecer el modo de adquisición de dominio, y fija como indicios para tener en cuenta que el bien es baldío el certificado negativo del registrador y la demanda dirigida contra indeterminados.

En salvamento de voto, el magistrado Palacio expresa que la Corte desconoció que la naturaleza jurídica del bien no fue probada en el proceso y por ende el problema jurídico no podría ser la trasgresión del ordenamiento jurídico por declarar la prescripción de un bien baldío en proceso de pertenencia, sino que la discusión se debió centrar en analizar los eventos en que no se tenga inscrito propietario privado en el folio de matrícula, para examinar si resultaba obligatorio la vinculación del INCODER.

\section{Postura de la Corte Suprema de Justicia}

A continuación se hace un análisis de algunas sentencias de la Corte Suprema de Justicia en adelante CSJ, específicamente emitidas en su Sala de Casación Civil, al igual que se hizo con las providencias de la Corte Constitucional, en donde se observa la postura sobre los bienes baldíos, las pruebas que se solicitan en un proceso de pertenencia, y el alcance de la presunción contenida en la ley 200 de 1936 sobre el tratamiento que se le da a un predio como privado cuando se verifique la explotación positiva económica de este.

En sentencia de la CSJ con expediente número 0504531030012007-00074-01 del 10 de septiembre de 2010, se indicó que la constitución y la ley prohíben la prescripción de los bienes fiscales porque su destinación está encaminada en el cumplimiento de los fines estatales y por tal motivo tienen un régimen especial para adquirirlos, y explica la existencia de una excepción cuando la posesión se ejerce antes de la vigencia del código de procedimiento civil. Además señala que la posesión es la tenencia con ánimo de señor y dueño sobre un cosa, y que se entiende como expectativa de adquisición del dominio, mientras no se cumpla el tiempo establecido legalmente.

De esta manera es claro que la CSJ sostiene la imposibilidad de imprescriptibilidad de los bienes baldíos, posición pacífica en nuestro ordenamiento jurídico, sin embargo existe un punto álgido sobre las cargas probatorias en los procesos de pertenencia, puesto que se debe esclarecer en quien debe recaer la obligación de demostrar si un bien es privado o baldío, esto con el fin de saber si puede operar la prescripción para adquirir el bien en litigio.

Así, en sentencia de la CSJ del 31 de octubre de 1994 (expediente número 4306), se resuelve un recurso de casación contra sentencia emitida por el Tribunal de Cundinamarca en proceso de pertenencia incoado contra personas indeterminadas sobre un inmueble rural, que en primera instancia se falló de forma favorable, sin embargo en grado de consulta el Tribunal revocó la sentencia y denegó las pretensiones de la actora, argumentando que en los procesos de pertenencia sólo pueden estar en litigio bienes inmuebles con la calidad de privados, y la naturaleza del bien del cual versa el proceso es dudosa dado que en la revisión del folio de matrícula inmobiliaria no se visualiza con claridad su naturaleza privada puesto que se encuentra que los registros inscritos corresponden a falsas tradiciones, por lo cual el Tribunal afirmó que no ha salido de la propiedad del Estado ni ha entrado a ser propiedad de particulares, entonces podría ser un bien baldío.

Así mismo, el Tribunal afirma no desconocer las presunción que consgara el artículo $1^{\circ}$ y $2^{\circ}$ de la ley 200 de 1936, sin embargo argumenta 
que la carga de la prueba la tiene la actora, demostrando suficientemente la legalidad de su pretensión, y entonces la demandante debería iniciar el procedimiento que se ha establecido legalmente en Colombia para obtener el título traslaticio de dominio de bienes baldíos, dado que por el procedimiento de pertenencia que ha incoado es imposible, puesto que estos bienes tienen una regulación específica y gozan de un calidad especial.

Contrario a lo esbozado por el Tribunal, la CSJ explica que la carga de demostrar que un bien no es baldío no debe estar en cabeza de quien demanda en un proceso de pertenencia, puesto que la ley no establece tal obligación, máxime cuando existe una presunción de propiedad privada cuando quien ostenta la posesión demuestra su explotación económica en los términos del artículo $1^{\circ}$ de la Ley 200 de 1936, y corresponde al Estado demostrar que el bien no ha salido de su propiedad y desvirtuar la presunción señalada. (Corte Suprema de Justicia, expediente número 4306, sentencia del 31 de octubre de 1994)

Se observa entonces que la CSJ realza el valor de la presunción de la explotación económica para determinar que el bien es privado, y traslada al Estado la carga de demostrar la calidad del bien, en contraposición con las posturas de los jueces que consideran que cuando en la matrícula inmobiliaria no están inscritos titulares de derecho reales se deba concluir prima facie que la naturaleza del bien es del Estado. Esto lo sustenta la CSJ al argumentar que por ley tal certificado no es para demostrar la calidad de privado de un bien sino que es un documento necesario para iniciar un proceso de pertenencia.

Siguiendo esta línea, en la sentencia con expediente número 5448 del 28 de agosto 2000 se resuelve el recurso de casación interpuesto por la demandante en contra de sentencia emitida por el Tribunal de Cundinamarca en proceso de pertenencia contra personas indeterminadas en donde se especifica que la demandante adquirió por medio de contratos de compraventa la posesión del fundo y registró dichos títulos en el folio de matrícula inmobiliaria; sin embargo el Tribunal no reconoce las inscripciones en la matrícula puesto que no se determina tradiciones del derecho de dominio como lo exige la ley ${ }^{3}$, por lo cual ante la carencia de registro que acredite su propiedad y naturaleza privada se presume que es un baldío. Es de anotar que para la CSJ en éste caso no existía titulares de derechos reales, pero sí inscritas las posesiones que sumadas superan el término legal, posesión pacífica, pública e ininterrumpida a través de una explotación económica permanente.

La CSJ al resolver el recurso de casación recuerda que no es posible considerar que un bien es baldío simplemente porque no obre registro de titulares de bienes reales en su matrícula inmobiliaria, dado que la finalidad del documento es conformar el litisconsorte necesario para iniciar el proceso de pertenencia. Así, la CSJ acepta la presunción del artículo $1^{\circ}$ de la ley 200 de 1936, y señala que al actor no se le debe exigir acreditar la naturaleza del bien pues no se debe desconocer que cuando lo explota económicamente tiene la calidad de propietario. (Corte Suprema de Justicia, sentencia con expediente número 5448 del 28 de agosto 2000 2000)

En reciente jurisprudencia de la CSJen sentencia número 1776 del 16 de febrero 2016, expediente número15001-22-13-000-2015-00413-01, se decidió la impugnación contra una sentencia dictada por el Tribunal de Tunja, en acción de tutela interpuesta por el INCODER contra el Juzgado Primero Civil del Circuito, debido al proceso de pertenencia que se promovió allí dirigida a personas indeterminadas.

En esta sentencia, el INCODER afirma que el juez de conocimiento omitió verificar la

3 Artículos: 756 del C. C, 3o. de la Ley 200 de 1936, 48 de la Ley 160 de 1994 y 52 del Decreto 1250 de 1970 
naturaleza jurídica del bien, y al observar que no tenía anteriores titulares debió advertir la posibilidad de que este fuera un baldío, por lo que se le debió vincular para señalar que este bien de ser baldío era imprescriptible. Además este Instituto argumentó, que siguiendo la legislación Colombiana, especialmente la Ley 160 de 1994, en su artículo 56, no se requirió dentro del proceso el documento adecuado para acreditar la propiedad privada sobre el bien el litigio. (Corte Suprema de Justicia, sentencia número 1776 del 16 de febrero 2016, expediente número15001-22-13-000-2015-00413-01 2016)

Inicialmente la CSJ expresa que en algunos eventos ha aplicado parcialmente la sentencia T-488 de 2014, argumentando que cuando no es posible esclarecer la naturaleza jurídica del bien en litigio es necesario vincular al INCODER para el esclarecimiento de esta situación.

La CSJ explica que la prueba para determinar la naturaleza de un bien no es el certificado expedido por el Registrado de Instrumentos Públicos, es decir no se puede entender como baldío un bien usando como argumento el certificado negativo del registrador, en cambio se debe tener presente la existencia de la presunción del artículo 1 de la ley 200 para dar lucidez del bien objeto del litigio, de esta manera se sostiene que si el particular logra demostrar que explota el bien conforme lo expresa la ley se puede concebir de propiedad privada, lo que pone en cabeza del Estado probar lo contrario, afirmando que no se ha explotado económicamente y presentar la calidad de bien baldío. (Corte Suprema de Justicia, sentencia número 1776 del 16 de febrero 2016, expediente número15001-22-13-000-2015-00413-01 2016)

En la sentencia la CSJ reconoce la imprescriptibilidad de los bienes baldíos, pero señala que se debe tener certeza sobre la naturaleza jurídica del bien, ya que si no se tiene, en caso de que el bien se haya explotado económicamente por una persona opera la presunción antes mencionada, y se está ante un predio de carácter privado que goza de la posibilidad de adquirirse por el modo de la prescripción y se debe respetar su posesión.

También afirma que no recae sobre el actor que pretenda la prescripción de un bien inmueble la carga probatoria de demostrar que el bien no es baldío y que efectivamente salió del patrimonio del Estado e ingresó al de un particular, al igual que no es válido afirmar que un bien es baldío al observarse que en el certificado expedido por el Registrador de la Oficina de Instrumentos Públicos no obra inscripción alguna de propiedad de derecho reales sobre el bien, dado que aceptar esta posición sería desconocer la posibilidad de la existencia de bienes privados que se han poseído a lo largo de la historia, pero que no han contado con el cumplimiento de las exigencias legales en cuanto a inscripción y registro.

Esta Sala precisa además que el certificado expedido por el registrador de la Oficina de instrumentos Públicos, como documento exigido para incoar la demanda de pertenencia, no se solicita con el fin de verificar si el bien es baldío, sino que obra en el expediente de un proceso de pertenencia para determinar, los legítimos contradictores titulares de derechos reales (Corte Suprema de Justicia, sentencia número 1776 del 16 de febrero 2016, expediente número15001-22-13-000-2015-00413-01 2016), sin embargo no tener titulares inscritos en dicho certificado o no tener abierto una matrícula inmobiliaria no es óbice para el trámite del proceso de pertenencia y admisión de la demanda ya que se realiza en contra de personas indeterminadas, pero debe anexarse a la demanda el certificado negativo expedido por la Oficina de Registro.

Para el caso concreto la CSJ observa que el bien en litigio es un bien privado, ya que el INCODER, no logró demostrar en el proceso lo contrario para desvirtuar la presunción de 
propiedad privada, y que cuando un inmueble no cuenta con anotación en el certificado inmobiliario, no constituye un indicio suficiente para determinarlo como un bien baldío y que se venza la presunción legal expuesta sobre la explotación económica de un bien.

De esta forma, la CSJ no sigue la línea de pensamiento la sentencia de la Corte Constitucionaldebidoaqueel carácter probatorio que allí se exige le resulta insuficiente, puesto que como se explicó anteriormente, para la CSJ el certificado expedido por el Registrado de la Oficina de Instrumentos Públicos no es el que permite determinar si un bien es baldío sino que su función es señalar quiénes serán los demandados en el proceso de pertenencia; además se desconoció la presunción de propiedad privada.

Así mismo, la CSJ afirma que la Corte Constitucional en sentencia T-488 de 2014 no tuvo en cuenta la explotación económica que demostraba el accionante, dando valor probatorio a que la demanda se interpuso en contra de personas indeterminadas y al certificado negativo del registrador, lo que consideró como indicios para decidir que el bien era baldío del cual no era posible la apropiación por prescripción, lo que lo conllevó, al desconocimiento de las presunciones legales que desde 1936 se establecen en el ordenamiento jurídico.

Análisis de la postura de la corte constitucional contenida en la Sentencia T 488 de 2014.

De lo expuesto es posible observar que la discusión no gira en torno a la prescripción de bienes baldíos, dado que desde los preceptos legales se prohíbe expresamente, por lo contrario se centra en un tema probatorio de gran importancia dentro de los procesos de pertenencia, toda vez que ante la falta de demostración de la naturaleza del bien objeto del proceso, de acuerdo con la CSJ se debe presumir que es propiedad privada si se demuestra en el proceso que está siendo explotado económicamente por el demandado, contrario sensu la Corte Constitucional en sentencia T-488 del 2014 afirma que no basta con probar la explotación económica sino que el INCODER deberá indicar la naturaleza del bien y si se encuentran dudas sobre ello, el juez de conocimiento deberá tener como indicios para sustentar que el bien es baldío e imprescriptible la falta de matrícula abierta del inmueble o de anotaciones que indiquen cadenas de dominio que conste en el certificado de la Oficina de Registro y la demanda contra personas indeterminadas.

De esta manera, se observa como la Corte Constitucional se aparta de la aplicación de la presunción de la ley 200 desconociendo su esencia y fuerza vinculante ya que las presunciones legales tienen un papel instrumental posibilitando la superación de situaciones en ausencia de elementos de juicio acreditados en un proceso, para que el juzgador resuelva en un sentido definido cuando existe incertidumbre frente al acaecimiento de circunstancias determinadas (Mendoca, 2000). Aunado a lo anterior, es evidente que con las presunciones se entiende como existente un hecho y se otorga efectos jurídicos a un supuesto fáctico de una norma, a partir de otro hecho probado en juicio que, en virtud de la ley, tiene conexión jurídica con éste (Álvarez, 2007) por lo tanto los jueces de conocimiento en los procesos de pertenencia deben declarar la prescripción adquisitiva a los bienes que no se logre comprobar que son baldíos, aplicando como regla de juicio la presunción en referencia, siempre y cuando se acredite con prueba directa la explotación económica del fundo.

En sentencia C-383 de 2000 la Corte Constitucional manifestó que una de las finalidades de las presunciones es equiparar las cargas de las pruebas para amparar a quien tenga mayor dificultad en probar un hecho; para el caso en análisis cuando se presume bien privado aquel que haya sido explotado 
económicamente, libera de la carga al particular de demostrar la naturaleza del bien, dado que para él presenta mayor dificultad acreditar que un bien salió de la esfera de propiedad del Estado y es de dominio de particulares, entonces equipara al demandante cuando se le permite probar que lo explota económicamente para ser adquirido por prescripción. Entonces, resulta contradictorio que la Corte Constitucional avale las presunciones y reconozca su aplicación al equilibrar los temas probatorios pero desconozca la aplicación de la presunción en referencia para los proceso de pertenencia.

Por lo anterior, no es dable exigirle al poseedor de tierras rurales que estén siendo explotadas económicamente la prueba de que el bien no es baldío, máxime cuando el INCODER manifiesta que no cuenta con un inventario de bienes baldíos, es decir, presenta gran dificultad acreditar la naturaleza del bien objeto del proceso tanto así que ni el mismo Estado tiene la capacidad de determinar con certeza la existencia de todos los baldíos en el territorio nacional.

Valencia Zea y Ortiz Monsalve expresan que "se presume que las tierras rurales explotadas económicamente no son baldías, es decir, que salieron del dominio de la nación, y sobra advertirlo, se presume además que esas tierras pertenecen a quien las explota actualmente" (2007, p. $335)$, entonces para que un bien inmueble sea adjudicado por la entidad gubernamental debe ser realmente baldío, es decir, si el poseedor del predio alega que el bien no es baldío porque lo está explotando económicamente, no cabe la adjudicación del inmueble sino la adquisición por prescripción toda vez que conforme con la presunción un fundo que esté siendo explotado económicamente se presume propiedad privada y frente a esta sólo cabe la prescripción adquisitiva en un proceso judicial de pertenencia, es decir la presunción de explotación económica convierte a un bien del cual no se tiene prueba cierta de su dueño en propiedad privada sacándolo del patrimonio del Estado.
Ahora bien, la Corte Constitucional en sentencia T-488 del 2014 intenta justificar su posición en indicios, como la ausencia de matrícula inmobiliaria abierta o de propietarios inscritos y la demanda contra indeterminados, sin embargo, cabe resaltar que la presunción de la ley 200 es de carácter legal y por tanto tiene mayor fuerza vinculante y obligatoriedad que los indicios que esgrime la Corte Constitucional; en otra oportunidad dicha Corporación expresó que no es cierto que cuando el registrador emite certificado negativo el juez puede declarar la prescripción sobre bienes baldíos, toda vez que el juez tiene poderes probatorios para buscar acreditar la naturaleza del bien (C-383 de 2000), es decir, se considera que en este pronunciamiento éste alto tribunal acepta que en el evento de que se tenga un certificado en sentido negativo no se constituye que el bien es imprescriptible, sino que el juez debe verificar la naturaleza del bien, para determinar su modo de adquisición de dominio.

Así mismo, jurídicamente no es válido afirmar que se tiene como indicio la falta de matrícula inmobiliaria toda vez que el ordenamiento jurídico prevé en el artículo 56 de la ley 1579 de 2012 que puede existir un inmueble sin matrícula inmobiliaria abierta y que el Registrador deberá abrirla cuando el interesado lo solicite con la sentencia ejecutoriada que declare la pertenencia.

Cabe advertir que la Corte Constitucional en sentencia T-488 de 2014 no desarrolla ningún argumento desestimando o en contra de la presunción legal en mención, su estructura, los hechos bases o presuntos, o la normalidad o habitualidad de la conexión entre el hecho base y el presunto, lo que implicaría un estudio juicioso y analítico para revisar la validez, vigencia, eficacia o fundamentos jurídicos que tiene dicha presunción, sino que omitiendo este examen intenta crear y argumentar unos indicios para acreditar la naturaleza de un bien; desconociendo que ante la incertidumbre debe aplicar la presunción legal puesto que 
esa es su función, aplicar supuestos fácticos de una norma (la prescripción adquisitiva de bien privado) cuando a partir de un hecho que se puede probar (explotación económica) se deduce que el hecho presunto (bien privado).

Por otro lado, en dicho pronunciamiento la Corte Constitucional deja de lado la función social de la propiedad y el mandato constitucional del artículo 64 que obliga a promover el acceso a la propiedad de la tierra a los trabajadores agrarios, ya que al desnaturalizar la presunción legal de la ley 200 establece una limitante para adquirir el bien que el demandante está explotando económicamente al imponer cargas adicionales para determinar la naturaleza del bien.

Al respecto la misma Corte en otras oportunidades ha dicho que es deber del Estado crear condiciones materiales para la dignificación de la vida de los trabajadores agrarios a través del acceso efectivo a la propiedad (C-189 de 2006) para materializar derechos fundamentales como el trabajo, la vivienda y el mínimo vital, y el derecho al acceso a la propiedad comprende la seguridad jurídica de las formas de tenencia de la tierra como la posesión o la propiedad, es decir, el Estado debe proteger el vínculo entre la población campesina y el territorio en el cual desarrollan su proyecto de vida ( C-623 de 2015), es decir, se impone una obligación al Estado para promover el acceso a la propiedad rural a la población campesina, pero prioritariamente se debe garantizar dicho acceso frente al predio que esté explotando económicamente en el cual se establece el poseedor, con el fin de mantener la seguridad jurídica del dominio sobre el fundo que el demandante en un proceso de pertenencia esté pretendiendo alcanzar.

Teniendo en cuenta el mandato que existe frente al acceso a la propiedad agraria para la población campesina por considerarse vulnerable, es claro que la garantía de acceso a la propiedad no sólo se garantiza adjudicando bienes baldíos (Corte Constitucional, C-595 1995), sino también haciendo efectiva la propiedad y la seguridad jurídica frente al bien que se esté explotando económicamente por el demandante en un proceso de pertenencia legalizando esta mediante la prescripción adquisitiva del dominio, de lo contrario, se impone una carga probatoria al demandante que imposibilita el acceso efectivo a la propiedad en desmedro de la seguridad jurídica del dominio frente al predio poseído, toda vez que el Estado tiene la obligación de determinar con claridad la naturaleza jurídica de los inmuebles (Art. 12 Ley 160 de 1994) mediante los procedimiento de clarificación y determinación de la propiedad de la Nación y de los particulares contenidos en el artículo 48 de la ley 160, no obstante el Estado no ha sido eficaz en el cumplimiento de estas obligaciones, puesto que si bien ha sido una preocupación del legislador colombiano garantizar el acceso a la propiedad a la población campesina, de acuerdo con el análisis realizado por la Corte Constitucional en sentencia C-644 de 2012 dichos esfuerzos muestran resultados negativos o, como lo acepta el INCODER en sentencia T-488 de 2014 al expresar que no cuenta con un inventario de bienes baldíos.

Así las cosas, no es dable poner mayores cargas a los particulares sobre la demostración de la naturaleza del bien en procesos de pertenencia teniendo en cuenta que los demandantes son personas en vulneración que deben ser protegidas de acuerdo con los mandatos constitucionales arriba explicados, que el gobierno no ha cumplido con sus obligaciones respecto al tema, y que existe una presunción legal que impone al juzgador dar por bien privado el inmueble explotado.

\section{Conclusiones}

De acuerdo con la legislación y la jurisprudencia patria la prescripción adquisitiva de dominio no aplica para bienes baldíos ya que estos sólo se adquieren por adjudicación mediante título traslaticio de dominio expedido por la 
entidad estatal competente. Sin embargo, ante la incertidumbre de determinar con certeza la naturaleza jurídica de un bien rural objeto de un proceso de pertenencia y teniendo en cuenta que en un proceso difícilmente se alcanza una verdad material y real, el juez ante los vacíos probatorios debe acudir a presunciones legales como reglas de juicio para tomar decisiones y resolver un caso partiendo de determinar la verdad formal o procesal que se logre acreditar en el proceso; por lo que si bajo las reglas de la presunción legal contenida en la ley 200 se acredita la posesión probando la explotación económica, el juzgador debe declarar la prescripción adquisitiva de dominio del bien a favor del demandante por considerarse un bien privado, siempre y cuando no se desvirtué dicha presunción; toda vez que al estar contenida en la ley dicha presunción tiene fuerza vinculante suficiente como para ser obligatoria la aplicación para los jueces.

Es claro entonces que en la presunción de la Ley 200, el demandante en el proceso de pertenencia deberá probar que la posesión del fundo consiste en la explotación económica del bien objeto de litigio (hecho base), y ante esto el juez deberá declarar fundado que el inmueble es propiedad privada (hecho presunto), siempre que no se demuestre lo contrario en el proceso, es decir, se debe acreditar en forma directa la explotación económica del bien para tenerse como cierto que es propiedad privada, puesto que de acuerdo con Aguiló (2006) mientras no se demuestre el hecho base no se configura el hecho presunto, entonces, el Estado en cabeza del INCODER o los demandados siempre tendrán la posibilidad de desvirtuar la presunción, descreditando la explotación económica o demostrando que el bien objeto del proceso es baldío, por lo tanto el juez de conocimiento del proceso de pertenencia no podrá declarar la prescripción del bien cuando efectivamente se acredite que el bien es un baldío.
Así las cosas, la presunción en mención favorece al demandante en los procesos de pertenencia al permitirle probar un hecho que es más fácil acreditar para adquirir por prescripción, pero no admitirá que un bien que se demuestre que es baldío sea adquirido por prescripción adquisitiva lo que resulta coherente con el ordenamiento jurídico en tanto los bienes baldíos son imprescriptibles. Se debe tener en cuenta además que el artículo 375 del CGP obliga a vincular al INCODER en los procesos de pertenencia para aclarar la naturaleza jurídica de los bienes en litigio, pero se debe entender que si no logra probar que es baldío el juez estará obligado a aplicar la presunción citada.

Por último, en cumplimiento del mandato constitucional del artículo 64 el Estado con el fin de garantizar el acceso a la propiedad de la población rural, debe tener en cuenta como una forma de amparar este derecho la adquisición del dominio de los predios que estén explotando económicamente y que no se logre demostrar en el proceso de partencia que son baldíos, vía prescripción adquisitiva de dominio, de lo contrario, se establecería un limitante más para acceder a la propiedad en condiciones de igualdad material, además se impondría una carga excesiva al demandante para demostrar la ausencia de característica de baldío frente a su predio, a sabiendas de la existencia de una presunción legal que lo favorece.

En conclusión, teniendo en cuenta lo explicado a lo largo del texto resulta desafortunado el pronunciamiento que tuvola Corte Constitucional en sentencia T-488 de 2014 ya que desconoce la obligatoriedad que tiene la presunción legal esbozada, se aparta de la garantía del acceso a la propiedad para la población campesina que históricamente ha sido vulnerable, creando indicios en contra de la presunción y dificultando la carga probatoria para los demandantes en los procesos de pertenencia de bienes rurales, y además premia la ineficaz tarea del Estado en la aclaración e inventario de los bienes baldíos. 


\section{Referencias}

Libros

Álvarez Sánchez de Movellán, P. (2007). La prueba por presunciones. Particular referencia a su aplicación judicial en supuestos de responsabilidad extracontractual. Granada, España: Editorial Comares.

Caicedo Escobar, P. (2001). Derecho inmobiliario registral. Registro de la propiedad y seguridad jurídica. Segunda edición. Bogotá, Colombia: Editorial Temis S.A.

Mendoca, D. (2000). Las claves del Derecho. Barcelona, España: Editorial Gedisa S.A.

Ochoa Carvajal, R.H (2006). Bienes, sexta edición. Bogotá, Colombia: Editorial Temis S.A

Valencia Zea, A., Ortiz Monsalve, A. (2007). Derecho Civil. Derechos reales. Tomo II. Bogotá, Colombia: Editorial Temis S.A

Artículos de revista

Aguiló Regla, J. (2006). Presunciones, verdad y normas procesales. ISEGORÍA (35), 9-35.

Bueso Sánchez, M. P. (2001-2002). De las presunciones e indicios. Anuario de la Facultad de Derecho (19-20), 449-456.

Casino Rubio, M. (2006). Presunción legal de culpabilidad versus prueba indiciaria de la autoría en las infracciones de tráfico. Revista de Administración Pública, mayoagosto (182), 85-120.

Palomo Vélez, D. (2013). Las cargas probatorias dinámicas: ¿Es indispensable darse toda esta vuelta? Revista lus et Praxis, Año 19 (2), 447-464.
Peláez Vargas, G. (1974). Indicios y presunciones. Revista Facultad de Derecho y Ciencias Políticas de la Universidad Pontificia Bolivariana (48), 49-72.

Zavala Toya, S. (1991). Las presunciones en el Derecho civil. (Tesis de maestría). Pontificia universidad Católica del Perú, Lima, Perú.

\section{Informes}

Consejo Superior de la Judicatura-Sala Administrativa; Escuela Judicial "Rodrigo Lara Bonilla". (2011). Derecho de pertenencia. Recuperado de http://www.ejrlb. com/biblioteca2011/content/pdf/a1/3.pdf

Instituto Colombiano de Desarrollo Rural INCODER. (2012). Memorias conceptuales del Instituto Colombiano de Desarrollo Rural- INCODER 2010-2012. Recuperado http://liquidacion.incoder. gov.co/documentos/A\%C3\%910_2015/ MODIFICACION\%20WEB\%202015/ NORMOGRAMA/Memorias\%20Conceptuales $\% 20$ INCODER\%202010\%20-\%20 2012.pdf

\section{Legislación}

Código Civil [CC]. Ley 57 de 1887. Mayo 26 de 1873. (Colombia)

Código de Procedimiento Civil [CPC]. Ley 1400 de 1970. Agosto 6 de 1970. (Colombia).

Código General del Proceso [CGP]. Ley 1564 de 2012. Julio 12 de 2012. (Colombia).

Decreto 1250 de 1970. Por el cual se expide el estatuto del registro de instrumentos públicos. Julio 27 de 1970. (Colombia) 
Decreto 2156 de 1970. Por el cual se modifica el Decreto-ley 1250 de 1970 y se dictan otras disposiciones. Noviembre 9 de 1970. (Colombia)

Decreto 1711 de 1984. Por el cual se dictan normas sobre interrelación de registro catastro y se tecnifica y reorganiza administrativamente el registro de instrumentos públicos. Julio 6 de 1984. (Colombia)

Decreto 1708 de 1989. Por el cual se fijan los derechos por concepto del registro de instrumentos públicos. Agosto 1 de 1989. (Colombia)

Decreto 2158 de 1992 [Presidencia de la República]. Por el cual se reestructura la Superintendencia de Notariado y Registro. Diciembre 30 de 1992. (Colombia)

Decreto 2664 de 1994 [Ministerio de agricultura y desarrollo rural]. Por el cual se reglamenta el Capítulo XII de la Ley 160 de 1994 y se dictan los procedimientos para la adjudicación de terrenos baldíos y su recuperación. Diciembre 3 de 1994 (Colombia)

Decreto 1669 de 1997 [Departamento Administrativo de la Función Pública]. Por el cual se suprimen y fusionan unas Dependencias de la Superintendencia de Notariado y Registro. Junio 27 de 1997. (Colombia)

Decreto 1428 de 2000 [Ministerio de Justicia y del Derecho]. Por el cual se fijan los derechos por concepto de la función registral y se dictan otras disposiciones. Julio 26 de 2000. (Colombia)

Decreto 2280 de 2008 [Ministerio del Interior y de Justicia]. Por el cual se fijan los derechos por concepto de la función registral y se dictan otras disposiciones. Junio 23 de 2008. (Colombia)
Ley 200 de 1936 . Sobre el régimen de tierras. Diciembre 16 de 1936 . DO. №23388 (Colombia).

Ley 137 de 1959. Por la cual se ceden derechos de la Nación al Municipio de Tocaima, y se dictan otras disposiciones. Diciembre 4 de 1959. DO No. 30136 (Colombia)

Ley 4 de 1973. Por la cual se introducen modificaciones a las Leyes 200 de 1936, 135 de 1961 y 1 a de 1968 . Se establecen disposiciones sobre renta presuntiva, se crea la Sala Agraria en el Consejo de Estado y se dictan otras disposiciones. Marzo 29 de 1973. (Colombia)

Ley 160 de 1994. Por la cual se crea el Sistema Nacional de Reforma Agraria y Desarrollo Rural Campesino, se establece un subsidio para la adquisición de tierras, se reforma el Instituto Colombiano de la Reforma Agraria y se dictan otras disposiciones. Agosto 5 de 1994. DO. No. 41479 (Colombia).

Ley 1579 de 2012. Por la cual se expide el estatuto de registro de instrumentos públicos y se dictan otras disposiciones. Octubre 1 de 2012. DO No. 48.570 de 1 de octubre de 2012 (Colombia).

\section{Jurisprudencia}

Corte Constitucional de Colombia. (1995). Sentencia C-595 de 1995. (Magistrado Ponente: Carlos Gaviria Díaz; Diciembre 7 de 1995).

Corte Constitucional de Colombia. (1996). Sentencia C-097 de 1996. (Magistrado Ponente: Carlos Gaviria Díaz; Marzo 7 de 1996). 
Corte Constitucional de Colombia. (1996). Sentencia C-530 de 1996. (Magistrado Ponente: Jorge Arango Mejía; Octubre 10 de 1996).

Corte Constitucional de Colombia. (1997). Sentencia C-536 de 1997. (Magistrado Ponente: Antonio Barrera Carbonell; Octubre 23 de 1997).

Corte Constitucional de Colombia. (2000). Sentencia C-388 de 2000. (Magistrado Ponente: Eduardo Cifuentes Muñoz; Abril 5 del 2000).

Corte Constitucional de Colombia. (2000). Sentencia C-383 del 2000. (Magistrado Ponente: Álvaro Tafur Galvis; Abril 5 del 2000.

Corte Constitucional de Colombia. (2006). Sentencia C-189 de 2006. (Magistrado Ponente: Rodrigo Escobar Gil; Marzo 15 de 2006).

Corte Constitucional de Colombia. (2006). Sentencia C-275 de 2006. (Magistrado Ponente: Álvaro Tafur Galvis; Abril 5 del 2006).

Corte Constitucional de Colombia. (2012). Sentencia C-255 de 2012. (Magistrado Ponente: Jorge Iván Palacio Palacio; Marzo 29 de 2012).

Corte Constitucional de Colombia (2012). Sentencia C-644 de 2012. (Magistrado Ponente: Adriana María Guillen Arango; Agosto 23 de 2012).
Corte Constitucional de Colombia. (2014). Sentencia T-488 de 2014. (Magistrado Ponente: Jorge Iván Palacio Palacio; Julio 9 de 2014).

Corte Constitucional de Colombia. (2015) Sentencia C-623 de 2015 (Magistrado Ponente: Alberto Rojas Ríos; Septiembre 30 de 2015).

Corte Suprema de Justicia de Colombia. Sala de Casación Civil. (1994). Sentencia con expediente número: 4306. (Magistrado Ponente: Nicolás Bechara Simancas; Octubre 31 de 1994).

Corte Suprema de Justicia de Colombia. Sala de Casación Civil. (2000). Sentencia con expediente número: 5448. (Magistrado Ponente: Jose Fernando Ramírez Gómez; Agosto 28 de 2000).

Corte Suprema de Justicia de Colombia. Sala de Casación Civil. (2010). Sentencia con expediente número: 050453103001200700074-01. (Magistrado Ponente: Fernando Giraldo Gutiérrez; Septiembre 10 de 2010).

Corte Suprema de Justicia de Colombia. Sala de Casación Civil. (2016). Sentencia con expediente número: 15001-22-13-0002015-00413-01. (Magistrado Ponente: Luis Armando Tolosa Villabona; Febrero 16 de 2016).

Forma de citar: Ocampo, M. (2016). Posturas jurisprudenciales sobre la determinación de la naturaleza jurídica del bien rural en procesos de pertenencia. Rev. CES Derecho, 7(2), 126-144. 